F Med Genet 2000;37 (http://jmedgenet.com/cgi/content/full/37/10/e26)

\section{Genetics and deafness: what do families want?}

EDITOR-Deafness is the most frequent sensory impairment in humans, with significant social and psychological implications. At least half of all cases of permanent childhood hearing impairment have a genetic cause. ${ }^{1}$ However, there is almost universal agreement among clinical geneticists that only a small proportion of such families are referred to clinical genetics services. ${ }^{2}$ Increasing public awareness of genetics in general will lead to increased demand. Therefore, what do families want and how should genetic services be planned?

Between September 1997 and October 1998, the parents of 522 hearing impaired children, aged between 4 and 13 years, in the Trent Health Region, were sent a questionnaire, which comprised 10 questions about their experience and opinion of clinical genetic services (see Appendix).

The families had been identified in a previous geographically defined, population based ascertainment study of childhood hearing impairment. ${ }^{3}$ A further 104 families identified by that study were excluded from the questionnaire survey because (1) they had indicated an unwillingness to participate in further research, (2) they were lost to follow up, (3) the child had died, or (4) a local professional had indicated an approach would not be appropriate. The majority $(n=416)$ of families were also sent an invitation to take part in a home visit, to investigate clinical aspects of non-syndromal hearing impairment. Those not invited to participate in a home visit $(n=106)$ were the families of children who had a named syndrome (with hearing impairment as a recognised association) or who had a definite diagnosis of meningitis. Eighty two families were visited as part of this aspect of the study. (These data are to be published elsewhere.)

Data from the previous study ${ }^{3}$ indicated that those not approached in the questionnaire survey were significantly less likely $(p<0.05)$ to have been referred for genetic counselling, but showed no significant differences in terms of age, gestational age, history of admission to a neonatal intensive care unit (NICU), family history of childhood hearing impairment, age of onset of hearing impairment, severity of impairment, evidence of progression of the impairment, or the presence of other medical problems.

Following one reminder, 182 questionnaires were returned, a response rate of $34.9 \%$ (182/522). This response rate is low, as might be expected for a postal questionnaire study on a subject area of possibly low interest and perceived relevance to many people. Families who
Table 2 Positive and negative experiences of formal genetic counselling

\begin{tabular}{|c|c|c|}
\hline & & No \\
\hline \multicolumn{3}{|l|}{ Diagnosis } \\
\hline \multirow[t]{8}{*}{ Positive } & Explanation about genetic mechanisms & 9 \\
\hline & Ability to establish cause & 5 \\
\hline & Absolution from self-blame & 3 \\
\hline & Full explanation of possible cause & 2 \\
\hline & $\begin{array}{l}\text { Reassurance that impairment is not associated with other } \\
\text { problems }\end{array}$ & 2 \\
\hline & Reassurance that impairment was not genetic & 2 \\
\hline & Learned a little more about possible cause & 1 \\
\hline & Reassurance that the impairment was not due to rubella & 1 \\
\hline \multirow[t]{2}{*}{ Negative } & Unable to establish a cause or mechanism & 16 \\
\hline & Unable to reassure and dispel feelings of self-blame/guilt & 3 \\
\hline \multicolumn{3}{|c|}{ Recurrence risks } \\
\hline Positive & Given recurrence risks & 12 \\
\hline \multirow{2}{*}{ Negative } & Unable to give meaningful recurrence risks & 3 \\
\hline & Led to termination of subsequent pregnancy & 2 \\
\hline \multicolumn{3}{|c|}{ Other information } \\
\hline \multirow[t]{3}{*}{ Positive } & Instigation of further investigations or referrals & 4 \\
\hline & Confirmation of previous assumptions and beliefs & 3 \\
\hline & Prognosis & 1 \\
\hline \multirow[t]{4}{*}{ Negative } & Vague and not well informed & 8 \\
\hline & Lack of investigation ("unscientific") & 5 \\
\hline & Difficult to understand & 2 \\
\hline & No information about research & 2 \\
\hline \multicolumn{3}{|c|}{ Logistics/practicalities } \\
\hline \multirow[t]{3}{*}{ Positive } & Opportunity for follow up & 5 \\
\hline & Opportunity to ask questions & 4 \\
\hline & Sufficient time made available for appointment & 1 \\
\hline \multirow[t]{6}{*}{ Negative } & No follow up & 6 \\
\hline & Insufficient time made available for appointment & 2 \\
\hline & Difficulty or delay in getting genetic counselling & 2 \\
\hline & Too early (genetic counselling too close to diagnosis) & 1 \\
\hline & Small consulting room & 1 \\
\hline & Poor "deaf awareness" & 1 \\
\hline \multicolumn{3}{|c|}{ Other statements } \\
\hline \multirow[t]{5}{*}{ Positive } & $\begin{array}{l}\text { Counsellors interested in family, kind and/or concerned to } \\
\text { help }\end{array}$ & 9 \\
\hline & $\begin{array}{l}\text { Information presented in an easy to understand and } \\
\text { interesting way }\end{array}$ & 9 \\
\hline & Comprehensive/holistic & 2 \\
\hline & Geneticist having positive attitude to condition & 1 \\
\hline & Advice about how to cope with child's special needs & 1 \\
\hline \multirow[t]{5}{*}{ Negative } & $\begin{array}{l}\text { General (not informative, "not impressed", "negative } \\
\text { attitude", etc) }\end{array}$ & 10 \\
\hline & Tedious repetition of questions previously answered & 1 \\
\hline & Some hostility to having answers questioned & 1 \\
\hline & Children not keen on blood tests & 1 \\
\hline & Shown "syndrome horror book" & 1 \\
\hline
\end{tabular}

did return completed questionnaires differed significantly from families who did not, only in that responders were more likely to have been referred for genetic counselling $(p<0.05)$. In terms of age, gestational age, history of admission to a neonatal intensive care unit (NICU), family history of childhood hearing impairment, age of onset of hearing impairment, severity of impairment, evidence of progression of the impairment, or the presence of other medical problems, this sample was representative of the overall population.

Sixty three families had received genetic counselling for hearing impairment from a recognised clinical genetic

Table 1 Experience of genetic counselling by assigned aetiology

\begin{tabular}{|c|c|c|c|c|c|c|}
\hline \multirow[b]{3}{*}{ Genetic counselling } & \multicolumn{6}{|l|}{ Aetiology } \\
\hline & \multirow[b]{2}{*}{ Environmental } & \multirow[b]{2}{*}{ Unknown } & \multirow[b]{2}{*}{ Perinatal } & \multicolumn{2}{|l|}{ Genetic } & \multirow[b]{2}{*}{ Total } \\
\hline & & & & Non-syndromic & Syndromic & \\
\hline Attended appointment with recognised clinical genetics service & 1 & 23 & 1 & 14 & 24 & 63 \\
\hline Declined or did not attend appointment for genetic counselling & 0 & 5 & 1 & 0 & 3 & 9 \\
\hline Had "genetic counselling" from alternative source & 0 & 3 & 1 & 2 & 1 & 7 \\
\hline Appointment not offered for genetic counselling & 23 & 39 & 14 & 14 & 13 & 103 \\
\hline Total & 24 & 70 & 17 & 30 & 41 & 182 \\
\hline
\end{tabular}


Table 3 What families most wanted from a clinical genetic service

\begin{tabular}{lll}
\hline & Responses & $\begin{array}{l}\text { \% of families responding to this } \\
\text { question }(n=130)\end{array}$ \\
\hline Definite diagnosis/cause & 76 & 58.5 \\
To address issues surrounding self-blame & 16 & 12.3 \\
Prognosis & 17 & 13.1 \\
Recurrence risks & 22 & 16.9 \\
$\quad$ For themselves (parents) & 38 & 29.2 \\
For their hearing impaired children & 20 & 15.4 \\
For their hearing children & 20 & 15.4 \\
Information about future advances and treatment & 8 & 6.2 \\
Follow up/review & 19 & 14.6 \\
More general information or improvement in other services & & \\
\hline
\end{tabular}

Table 4 Recurrence risk $(R R)$ as documented in health service notes and as remembered by families

\begin{tabular}{|c|c|c|c|c|c|c|}
\hline \multirow[b]{2}{*}{$R R$ reported by families } & \multicolumn{6}{|c|}{$R R$ documented in health service notes } \\
\hline & $1: 2$ & $1: 4$ & $1: 6$ & $\begin{array}{l}1: 6 \text { to } \\
1: 10\end{array}$ & $\begin{array}{l}\text { Information given on recessive } \\
\text { and dominant inheritance }\end{array}$ & $\begin{array}{l}\text { No } R R \\
\text { given }\end{array}$ \\
\hline $1: 2$ & 1 & & 1 & & & \\
\hline $1: 4$ & & 3 & 4 & 1 & & \\
\hline $1: 6$ & & 1 & 1 & & & \\
\hline $1: 6$ to $1: 10$ & & & & & & \\
\hline $1: 10$ & & & 1 & & & \\
\hline $1: 20$ & & & 1 & & & \\
\hline A girl would be impaired & 1 & & & & & \\
\hline A boy would be impaired & & & 1 & 1 & & \\
\hline $\begin{array}{l}\text { Information given on recessive and } \\
\text { dominant inheritance }\end{array}$ & & & & & 1 & \\
\hline No RR given & & & & & & 1 \\
\hline Can't remember & 1 & 2 & 2 & 3 & & 1 \\
\hline
\end{tabular}

service $(34.6 \%, 63 / 182)$. In addition, seven families said they had received "genetic counselling" from a variety of other sources: general physician with no specific qualification in genetic counselling $(n=3)$, ENT surgeon $(n=2)$, community paediatrician $(\mathrm{n}=1)$, and another researcher $(n=1)$. Nine families had been offered genetic counselling, but either did not attend $(n=3)$ or declined the offer at the time $(n=6)$. All six families who declined, said that this was because they were unable to cope with another hospital appointment at a time of great stress. Thus, 79 families $(43.4 \%)$ had an opportunity for some form of genetic counselling.

Of the 103 families not offered any genetic counselling, approximately half said they would like to have been $(51.5 \%, 53 / 103)$. Forty four $(55.7 \%, 44 / 79)$ of the children whose families were offered genetic counselling were assigned a genetic (non-syndromic or syndromic) aetiology, from all data available to the study, compared with only $27(26.2 \%, 27 / 103)$ of those not offered genetic counselling. In contrast, three families offered counselling were assigned a perinatal aetiology and only one an environmental aetiology compared with 14 perinatal and 23 environmental who were not offered counselling. These data are summarised in table 1 . The differences between the aetiology groups for those offered some sort of genetic counselling $(n=79)$ and those not offered any $(n=103)$ is significant $\left(\chi^{2}=28.7, \mathrm{df}=4, \mathrm{p} \leqslant 0.001\right)$.

Respondents were asked what they thought was good about the counselling they received and what was not so good. Sixty families made comments equally distributed between positive and negative. These are grouped and listed in table 2. Positive comments focused on informed explanation of possible cause and recurrence risks. However, an equal number of negative comments concerned the frustration and disappointment associated with lack of a firm diagnosis or clear cause, and the problems of one off appointments at inappropriate times. Major misconceptions about what genetics could offer were apparent.

The question "What would you most want from a Clinical Genetic service?" produced responses from 130 families, shown in table 3 , the commonest being requests for information about the causes of their child's (or children's) hearing impairment and information on recurrence risks for the parents, the hearing impaired children, and their hearing sibs.

Of the 82 families visited as part of the clinical part of this study, 34 had received formal genetic counselling between 1986 and 1996 and they were asked about this during the home visit, particularly whether they could remember being given a particular recurrence risk for having another hearing impaired child. The notes of 29 of these families who were seen by local clinical genetics services were also reviewed. The relevant notes of the families given counselling by sources other than recognised clinical genetics service were not available. Nine families could not remember the recurrence risk quoted and 13 actually recounted a different risk from that recorded as given in the notes. The parent's recollection of the recurrence risk exactly matched that quoted in the notes in only seven families $(24.1 \%, 7 / 29)$ (table 4$)$. Nine families (31\%) could not remember and $13(44.8 \%)$ did not remember exactly the recurrence risk they were given at formal genetic counselling. These numbers are too small to show statistical significance between the groups in terms of aetiology or satisfaction.

Although the response rate to this questionnaire survey is low $(34.9 \%)$, the sample who responded are representative of the population and thus the results may be considered as indicative of families' views of counselling as provided in the late 1980s and early 1990s. Service provision has certainly increased since that time but there is no direct evidence that it has improved. Further work on recently diagnosed children would be needed to address this question now.

The results show that a sizeable number of families with hearing impaired children are not being offered genetic services. Families given access to genetic counselling describe positive and negative experiences in equal proportion. They primarily seek information about cause and recurrence risks. A substantial proportion of those not offered genetic counselling would like to have been. It is 


\section{Table 5 Take home messages}

(1) Genetic counselling should be available to all families with children with permanent hearing impairment. The only exceptions would be the relatively few families with children with a definite environmental cause, for example, meningitis, congenital rubella.

(2) Families given access to genetic counselling do have negative experiences which should be addressed.

(3) Approximately half of families with hearing impaired children not offered genetic counselling would like to have been

(4) Children should be investigated systematically, in particular to exclude a syndromal aetiology. There should be an agreed national standard for such an investigation protocol.

(5) Genetic counselling should be an ongoing process with the opportunity for follow up appointments and review.

(6) There is a need for education about the significance of genetic factors in childhood hearing impairment, both of the public and health care professionals There is a need for education about the significan
involved in providing services for such families

important to ensure that the service provided is meeting the needs of the people it serves.

Genetic counselling should be available to families not just at the time of initial diagnosis, but when families feel best able to assimilate such information. It should not just be seen as a one off offer at a time when families are probably least able to appreciate wider implications of the diagnosis. There will be some families with strong negative views towards "genetics" and their views should be respected. ${ }^{4}$

It is worrying that a sizeable proportion of those families who have had genetic counselling cannot remember correctly what recurrence risks they were quoted. Letters to families summarising genetic counselling sessions and follow up appointments could help towards minimising this.

The introduction of universal neonatal hearing screening means that more hearing impaired children will be detected early, allowing parents the opportunity to be informed about their recurrence risks while still relevant to their own family planning. Systematic investigation of the child is crucial, ${ }^{2}$ in particular to exclude an environmental or syndromal aetiology. Such investigation should be considered as a dynamic process, as some syndromal associations may only become manifest as a child grows older.

\section{Appendix Families' questionnaire}

\section{Clinical Genetic Study of Childhood Hearing Impairment}

\begin{tabular}{|c|}
\hline $\begin{array}{l}\text { Questionnaire for Families } \\
\text { about }\end{array}$ \\
Clinical Genetics Services \\
\hline
\end{tabular}

Sometimes there is a definite cause for a child's hearing loss (such as an infection), but usually it either runs in the family or the cause is simply unknown. Children with hearing impairment and their family are sometimes given an appointment to see someone in a Clinical Genetics department for more information.

Clinical Genetics is a hospital department that exists to:

- explain to people about certain conditions that can run in the family

- provide information about the future for people with such conditions

- inform them of the chances of children with similar problems being born

- put people in touch with other hospital departments (if appropriate)

- help put people in touch with support groups

The results from this study will help us to understand more about what families like yours want from the Clinical Genetics Service. We hope it will enable us to plan a better service for the future.

We would like your family to help us by filling in this questionnaire.

Any information you give us will be treated in total confidence.
Your answers will be stored on computer at the Institute of Hearing
Research and will meet the terms of the Data Protection Act.
They will be destroyed when they are no longer needed.
This will not be shown to anyone involved in the health-care or
education of your child.
Your family's identity will not be revealed when any results are
reported.

Clinical genetics services will play a pivotal role in coordinating the investigation and counselling of such families (table 5).

The authors wish to thank all those who participated in this study, in particular Dr Sally Hind from the MRC Institute of Hearing Research. Dr Parker was funded by a grant from the NHS Executive Trent, Research and Development Directorate.

M J PARKER ${ }^{\star} \dagger$ H M FORTNUM† I D YOUNG

A C DAVIS†

*Department of Clinical Genetics, Leicester Royal Infirmary, Leicester, UK

†MRC Institute of Hearing Research, University Park, Nottingham NG7 2RD, UK

$\ddagger$ Department of Clinical Genetics, City Hospital, Nottingham, UK

Correspondence to: Dr Parker, mick@ihr.mrc.ac.uk

1 Reardon W. Genetic deafness. F Med Genet 1992;29:521-6.

2 Parker MJ, Fortnum H, Young ID, Davis AC. Variations in genetic assessment and recurrence risks quoted for childhood deafness: a survey of clinical geneticists. 7 Med Genet 1999;36:125-30.

3 Fortnum HM, Davis AC. Epidemiology of permanent childhood hearing impairment in Trent Region, 1985-1993. Br f Audiol 1997;31:409-46.

4 Middleton A, Hewison J, Mueller RF. Attitudes of deaf adults toward genetic testing for hereditary. Am f Hum Genet 1998;63:1175-80.

ABOUT YOU AND YOUR FAMILY:

The following details will help us to look at the results in a more useful way. If you do not wan to fill in this part, please begin the questionnaire at Question 1.

Your post code:
Your children:
$\begin{array}{llll} & & \\ \text { Please fill in the date of birth for each of your children and tick the box to say if they are } \\ \text { hearing-impaired or not }\end{array}$
$\begin{array}{llll}\text { Date of birth } & \text { Hearing impaired } & \square \text { Yes } & \square \text { No } \\ \text { Date of birth } & \text { Hearing impaired } & \square \text { Yes } & \square \text { No } \\ \text { Date of birth } & \text { Hearing impaired } & \square \text { Yes } & \square \text { No } \\ \text { Date of birth } & \text { Hearing impaired } & \square \text { Yes } & \square \text { No } \\ \text { Date of birth } & \text { Hearing impaired } & \square \text { Yes } & \square \text { No }\end{array}$

1) What, to thc best of your knowledge, is the cause of your ehild's hearing loss?

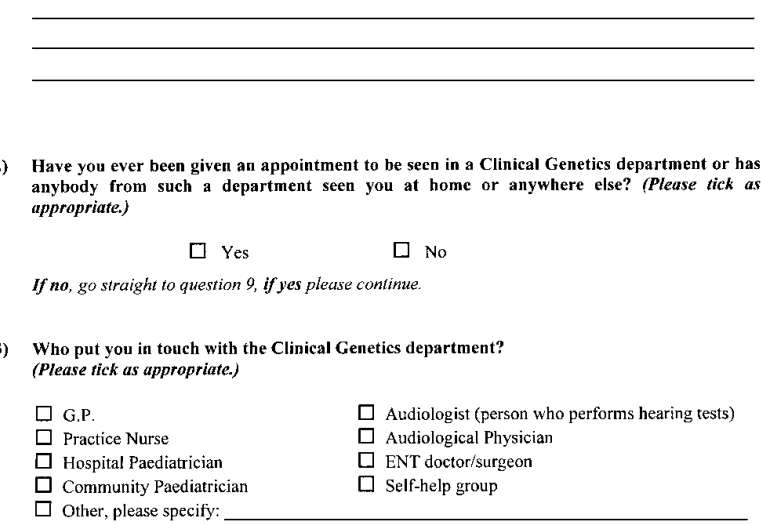


4) Did you take up this Clinical Genetics appointment? (Please tick as appropriate.)

$$
\square \text { Yes }
$$

If no, go straight to question 8 , if yes please continue.

5) Please tell us who you saw and where (if you can remember).

6) Please write down what you thought was good about this appointment/meeting (as many as you wish).

7) Please write down what you thought was not so good about this appointment/meeting (as many as you wish).

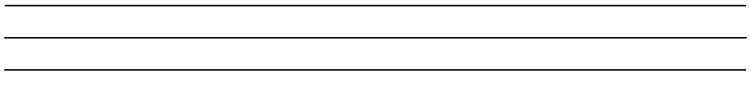

Please go to question 10

8) If you did not take up this appointment, please tell us your reasons (write as many as you wish)?

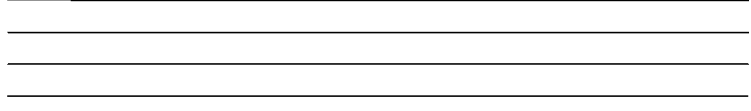

Please go to question 10

9) If you have never been given a Clinical Genetics department appointment, would you like to If you have never been given a Clinical
have been (please tick as appropriate)?

$\square$ Yes

$\square$ No
10) What would you most want from a Clinical Genetic service (write as many as you wish, in their order of importance to you)?

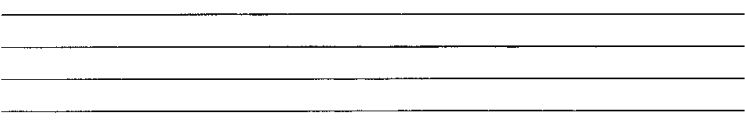

Any other comments:

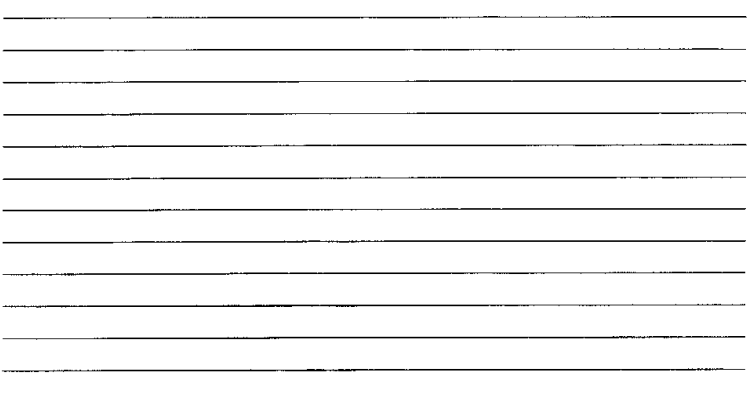

Thank you

PLEASE RETURN THE QUESTIONNAIRE IN THE ENCLOSED REPLY-PAID ENVELOPE

(you do not need a stamp) TO:

Dr Michael Parker Clinical Genetics Research Fellow Medical Research Council Institute of Hearing Research

University Park

Nottingham

Telephone: 01159223431

Minicom: 01159518509

Fax: 01159518503

e-mail: mick@ihr.mrc.ac.uk 